\title{
Postoperative cognitive dysfunction in patients of the elderly and old age operated for composition of objective cancer
}

\author{
N. I. Glushkov1, T.L.Gorshenin ${ }^{1,2}$, M. A.Privalova ${ }^{1,2}$, \\ G. S. Gugalev ${ }^{3}$, S. K. Dulaeva ${ }^{1,2}$ \\ ${ }^{1}$ North-Western State Medical University named after I. I. Mechnikov, \\ 41, Kirochnaya ul., St. Petersburg, 191015, Russian Federation \\ 2 St. Petersburg Hospital for War Veterans, \\ 21, ul. Narodnaya, St. Petersburg, 193079, Russian Federation \\ ${ }^{3}$ City Polyclinic no. 43, \\ 123, Leninsky pr., St. Petersburg, 198207, Russian Federation
}

For citation: Glushkov N. I., Gorshenin T.L., Privalova M. A., Gugalev G. S., Dulaeva S. K. Postoperative cognitive dysfunction in patients of the elderly and old age operated for composition of objective cancer. Vestnik of Saint Petersburg University. Medicine, 2021, vol. 16, issue 1, pp. 37-42. https://doi.org/10.21638/spbu11.2021.104

The problem of preserving the quality of life in the postoperative period, one of the criteria of which is the cognitive function, retains its relevance. In patients with advanced and senile age, after undergoing surgery, cognitive disorders are swept aside, which, according to various authors, reaches $64 \%$. Postoperative cognitive dysfunction was studied in 168 elderly and elderly patients operated on for complications of colon cancer. Patients were divided into two groups. Patients of the control group were operated on operations conventionally, the main one - laparoscopically, using endovideosurgical technologies. Cognitive status was assessed before the operation, as well as on the first, third and seventh days of the postoperative period using the MMSE test (abbr. English Mini Mental State Examination). The incidence of postoperative cognitive dysfunction in both groups was traced. In the development of postoperative cognitive disorders, along with such factors as general anesthesia, age, aggravated neurological history, depressive disorders, operative trauma plays an important role. The use of endoscopic technologies allows reliably reducing the risk of postoperative cognitive impairment, which in turn has a beneficial effect on the postoperative period.

Keywords: colon cancer, cognitive dysfunction, surgical treatment, postoperative period, elderly and old age.

\section{Introduction}

Problem of colon cancer treatment continues to preserve its actuality due to high incidence of the disease and large amount of firstly revealed protracted forms. Elder than 60 years patients constitute $72.5 \%$ among diseased by colon cancer, and those who are elder than 70 years $-42.5 \%$. Burdened by accompanied cardiovascular and pulmonary pathologies in patients of elderly and senile age, suffered from colon cancer, attains $100 \%$ [1].

In majority of the patients with colon cancer this disease is diagnosed at III-IV stages, therewith most of all late appealability is noted in case of elderly and senile patients, who underestimate first signs of colon cancer, because often colon cancer developed at the background prolonged existing enteropathies: diverticular disease, chronic colitis,

(C) St. Petersburg State University, 2021 
functional bowel disorders a so on. As a result of late colon cancer verification, majority of patients admitted to general surgical hospitals for complications of this disease [2]. It is considered that complicated colon cancer will for a long time occupy leading positions among oncology diseases in general surgical hospitals [3]. Among the patients with complicated forms of cancer, patients of elderly and senile age constitute from $42.5 \%$ to $86.2 \%$ [4]. In spite of late appealability and presence of complications, the aim of surgical colon cancer treatment is not only to prolong patient's life, but also to preserve its quality, criteria of which are preserving social activity an cognitive functions. Performed survey investigation of wide range of respondents in respect of the most important indices of anaesthesia quality demonstrated that patients and their relatives the most significant for them consider personnel comfort preservation in postoperative period, ability to full interaction, ability of letter writing and reading, former ability to work [5]. Recently a large number of works are devoted to postoperative cognitive dysfunction. Postoperative cognitive dysfunction (POCDF) - it is cognitive disorder, developed in early and remained in remote postoperative period. Clinical cognitive disorder appeared in the form of memory impairment, problems with attention concentrating and its focusing, disorder of other higher cortical functions: thinking, speech, remembering. Sometimes postoperative cognitive dysfunction may be accompanied by depressive and anxious syndromes, which are diagnosed mainly by the data of neuropsychological testing [6].

In senior age group development of cognitive disorders in early post operative period constitute, according to different authors, from 18 to $64 \%$ [7]. Recently many researchers consider the main reason of POCDF development is general anaesthesia medicinal drugs impact, which provide neurotoxical impact [8]. Nevertheless, there exists another point of view, according to which POCDF appeared as a result of combined surgical intervention aggressive factors impact, the main of which are the following: duration and injury of surgical intervention, anaesthesia technique, elderly and senium age of patients, accompanied pathology of central nervous system [9]. Considering high percent of elderly age groups, admitted with complicated forms of colon cancer to emergency departments of general surgery, the question concerning preservation of mnestic functions in postoperative period is one of the actual aspects in medical aid quality provision.

Purpose of the work - to estimate POCDF in patients of elderly and senile age, operated for colon cancer complications depending of the surgical intervention method.

\section{Material and methods}

This research included 168 patients, operated for colon cancer complications ion general surgery department in Saint-Petersburg hospital of war veterans from 2012 to 2016. Age of patients varied from 60 to 95 years, constituted in average 82.3 years. There were 118 women $(70.2 \%)$ and 50 men $(29.8 \%)$. All the patients were divided in two groups. Control group consisted of 90 persons (53.6\%), who were operated conventionally due to colon cancer complications. The main group consisted of 78 (46.4\%) patients (Table 1).

They were subjected to minimally invasive surgical intervention for colon cancer complications using endovideosurgery technologies. Contraindication to operations with endovideosurgery technologies we divided on absolute and relative, local and general ones. To local absolute contraindications were: signs of decompensated intestinal obstruction with homeostasis disorders; prence of multiple postoperative cicatrixes, occupying over 
Table 1. Distribution of patients by sex and age

\begin{tabular}{|l|c|c|c|c|c|c|c|}
\hline \multirow{3}{*}{ Groups } & \multicolumn{9}{|c|}{ Age } & \multirow{2}{*}{ Total } \\
\cline { 2 - 8 } & \multicolumn{2}{|c|}{$\mathbf{6 0 - 7 5}$} & \multicolumn{2}{c|}{$76-90$} & \multicolumn{2}{c|}{$>90$} & \\
\cline { 2 - 8 } & M & F & M & F & M & F & \\
\hline Main & 8 & 23 & 18 & 38 & 1 & 2 & 90 \\
\hline Control & 7 & 21 & 16 & 33 & 0 & 1 & 78 \\
\hline Total & 15 & 44 & 34 & 71 & 1 & 3 & 168 \\
\hline
\end{tabular}

a halve of anterior abdominal wall area or functioning fecal fistulas; widespread peritonitis older than $12 \mathrm{hr}$; intestinal loops hyperextension, in which case nasointestinal intubation is required. To local relative contraindications were: large unreducible ventral hernias, unformed intestinal fistulas, total adhesions of abdominal cavity. General absolute contraindications included acute cardiovascular disorders (acute ischemic heart syndrome, AIHS), disorders of the main systems and functions of organism in decompensation stage. To general relative contraindications were: unstable angina, bronchial asthma with frequent aggravations, IV stage obesity, portal hypertension, tolerated massive radiation therapy. All the patients had a heavy comorbide background, mainly due to cardiovascular and neurological pathologies. Often in one patient we observed up to five simultaneously existing chronic diseases. Influence of comorbidity at the course of perioperative period was estimated using age dependent coefficient of M. Charlson. In the recent research this coefficient varied from 6 to 12 , constituting in average 9.2. Risk of the future operative intervention was estimated using ASA scale. In majority of patients $3^{\text {th }}$ and $4^{\text {th }}$ stage of operative-anesthetic risk was noted. Among colon cancer complications most frequently acute bowel intestinal obstruction was noted - 107 (63.7\%), rarely perifocal inflamation - 31 (18.5\%), bleeding - $25(14.9 \%)$ and tumor perforation $-5(2.9 \%)$. This research included patients who were subjected to resection surgical interventions on large bowel.

Cognitive status was estimated before the operation, and also at $1^{\text {st }}, 3^{\text {rd }}$ and $7^{\text {th }}$ day after operation by means of MMSE-test (Mini Mental State Examination). At the moment of arrival in majority of patients cognitive disorders were noted, which were stipulated by chronic insufficiency of cerebral circulation against the background of atherosclerotic vascular disease of cerebral arteries, and also as a result of toxic syndrome, caused by colon cancer complications (Table 2).

Table 2. Rate of cognitive disorders expressivity before surgical treatment at the moment admission to hospital

\begin{tabular}{|l|c|c|c|}
\hline \multicolumn{1}{|c|}{ Rate of cognitive disorders expressivity } & $\begin{array}{c}\text { Main group } \\
(\mathbf{n}=78)\end{array}$ & $\begin{array}{c}\text { Control group } \\
(\mathbf{n}=\mathbf{9 0})\end{array}$ & $\begin{array}{c}\text { Total } \\
(\mathbf{n}=168)\end{array}$ \\
\hline Without cognitive disorders (28-30 scores) & $32(41 \%)$ & $38(42.2 \%)$ & $70(41.7 \%)$ \\
\hline Light cognitive disorders $(24-27$ scores) & $27(34.6 \%)$ & $23(25.6 \%)$ & $50(29.8 \%)$ \\
\hline Moderate cognitive disorders (20-23 scores) & $16(20.5 \%)$ & $19(21.1 \%)$ & $35(20.8 \%)$ \\
\hline Expressed cognitive disorders (11-19 scores) & $3(3.9 \%)$ & $10(11.1 \%)$ & $13(7.7 \%)$ \\
\hline Heavy dementia $(0-10$ scores) & 0 & 0 & 0 \\
\hline
\end{tabular}


All the submitted persons were operated in emergency order by conventional or minimal invasive method. Combined surgical anaesthetization was performed: pulmonary endotracheal anesthesia with reinforcing phentanyl injection, muscle relaxation and prolonged peridural anesthesia.

By age, gender composition, presence and severity of accompanying pathology, localization and stage of neoplastic (tumor) process in large intestine, as well as by the rate of operative-anaesthetic risk all the patients in the main and control groups were presented evenly.

Statistical treatment of the results was carried out by means of program Statistica 7.0 for Windows and Microsoft Excel. Analysis of average values difference reliability was performed by Student's test ( $\mathrm{t}$-criterion), estimation of qualitative attributes contingency was performed using Pirson criterion $\chi^{2}$. Obtained results at values $\mathrm{p}<0.05$ were considered statistically significant.

\section{Results of investigation}

At first day of postoperative period in all the patients from control group incresing of cognitive disorders was noted, up to full dementia by MMSE scale (that estimate is not a diagnosis and only demonstrate the rate of cognitive deficit at the moment of the research) (Table 3).

Table 3. Dynamics of after operation cognitive disorders in control group

\begin{tabular}{|l|c|c|c|c|}
\hline \multirow{2}{*}{ Rate of cognitive disorders expressivity } & \multicolumn{3}{|c|}{$\begin{array}{c}\text { Time frames of postoperative cognitive disorders } \\
\text { investigations }\end{array}$} \\
\cline { 2 - 5 } & \multirow{2}{*}{$\begin{array}{c}\text { Before } \\
\text { operation }\end{array}$} & \multicolumn{3}{|c|}{ Postoperative period } \\
\cline { 3 - 5 } & & 1 day & 3 day & 7 day \\
\hline Without cognitive disorders (28-30 scores) & $38(42.2 \%)$ & $18(20 \%)$ & $22(24.4 \%)$ & $25(27.8 \%)$ \\
\hline Light cognitive disorders $(24-27$ scores $)$ & $23(25.6 \%)$ & $18(20 \%)$ & $20(22.2 \%)$ & $25(27.8 \%)$ \\
\hline Moderate cognitive disorders $(20-23$ scores) & $19(21.1 \%)$ & $24(26.7 \%)$ & $22(24.4 \%)$ & $23(25.6 \%)$ \\
\hline Expressed cognitive disorders $(11-19$ scores) & $10(11.1 \%)$ & $23(25.6 \%)$ & $20(22.2 \%)$ & $13(14.4 \%)$ \\
\hline Heavy dementia (0-10 scores) & 0 & $7(7.7 \%)$ & $6(6.7 \%)$ & $4(4.4 \%)$ \\
\hline
\end{tabular}

Note: $\mathrm{p}<0.05$.

According to MMSE scale, decrease of test responds on 4-18 scores was recorded (8.2 scores in average). At that period a number of patients without cognitive dysfunctions deceased over than twice and a number of patients with expressed cognitive disorders increased over than twice. At the $3^{\mathrm{d}}$ day of postoperative period a certain positive dynamics in cognitive status of the patients was observed: in all the patients with cognitive disorders have improved MMSE testing passage on 3-4 scores. The same slow tendency was noted at $7^{\text {th }}$ day of postoperative period. As a whole, in the group of patients, who were operated by conventional method, restoration of cognitive functions was slower than in the main group. Besides, restoration of expressed cognitive disorders, up to full dementia, was observed in patients with complicated course of postoperative period. 
Table 4. Dynamics of after operation cognitive disorders in the main group

\begin{tabular}{|l|c|c|c|c|}
\hline \multirow{2}{*}{ Rate of cognitive disorders expressivity } & \multicolumn{4}{|c|}{$\begin{array}{c}\text { Time frames of after operation } \\
\text { cognitive disorders investigations }\end{array}$} \\
\cline { 2 - 5 } & \multirow{2}{*}{$\begin{array}{c}\text { Before } \\
\text { operation }\end{array}$} & \multicolumn{2}{|c|}{ Postoperative period } \\
\cline { 3 - 5 } & 1 day & 3 day & 7 day \\
\hline Without cognitive disorders (28-30 scores) & $32(41 \%)$ & $30(38.5 \%)$ & $36(46.2 \%)$ & $38(48.7 \%)$ \\
\hline Light cognitive disorders (24-27 scores) & $27(34.6 \%)$ & $28(35.8 \%)$ & $33(42.3 \%)$ & $35(44.9 \%)$ \\
\hline Moderate cognitive disorders (20-23 scores) & $16(20.5 \%)$ & $18(23.1 \%)$ & $8(10.2 \%)$ & $4(5.1 \%)$ \\
\hline Expressed cognitive disorders (11-19 scores) & $3(3.9 \%)$ & $2(2.6 \%)$ & $1(1.3 \%)$ & $1(1.3 \%)$ \\
\hline Heavy dementia (0-10 scores) & 0 & 0 & 0 & 0 \\
\hline
\end{tabular}

Note: $\mathrm{p}<0.05$.

In patients from the main group at the first day after surgical intervention insignificant decrease of cognitive functions was observed (average at 2.4 scores) (Table 4). At the third day after operation positive dynamics in the form of cognitive function improvement was observed. Average score by MMSE scale at that period constituted 26.3. At the seventh day after operation remained positive tendency in cognitive functions improvement. At that, number of patients without cognitive disorders or with light cognitive disorders exceeded the number of patients from the main group before operation. This circumstance to our mind may be explained by that along with cerebral vascular diseases, cognitive disorders were also stipulated by appeared colon cancer complications, which firstly caused intoxication. Performed operation removed developed complications and the tumor itself. The course of postoperative period for patients from the main group was more favorable, accompanied by less amount of complications and with decreased postoperative bed-days amount.

So, on the basis of performed investigation, it is possible to resume, that in POCDF development along with such factors as general anesthesia, age, burdened by neurological anamnesis, depressive disorders, significant role plays operative trauma, which in the given context is a sum of physical damages, local, directly related with surgical intervantion and damages of central nervous system of different genesis (from malfunction of brain structures antinociceptive protection support at the required level, damage due to hypoxemia, residual effect of anaesthesia components and so on).

\section{Conclusions}

Along with such unfavorable factors as general anaesthesia, age, burdened by neurological anamnesis, oftern accompanied by mnestical disorders, depressive disorders, significant role in postoperative disorders development plays operative trauma.

Investigation of cognitive status before and after operation enables to timely reveal cognitive disorders and to perform necessary medicamental correction in holspital conditions. 
Application of endovideosurgery technologies as the least traumatic enables to decrease reliably risk of postoperative cognitive disorders development, that in turn, provide a good effect on the course of postoperative period and on the further patient's complete restoration.

\section{References}

1. Novikov A. Yu., Kovalev V. A., Vinichuk N. V., Chernykh Yu. A., Golub I. E., Sorokina L. V. Prevention and correction of cognitive impairment after general anesthesia. Zhurnal nevrologii i psikhiatrii, 2017, vol. 117, no. 6, pp. 28-31. (In Russian)

2. Ovezov A.M., Knyazev A.V., Pateleeva M.V. Postoperative encephalopathy: pathophysiological and morphological bases of prevention in general anesthesia. Nevrologiya, neyropsikhiatriya, psikhosomatika, 2015, vol. 37, no. 2, pp. 61-66. (In Russian)

3. Popugaev K. A., Savin I. A., Goryachev A.S. Delirium in neuroresuscitation. II National Congress. Neotlozhnyye sostoyaniya v nevrologii. Moscow, 2011, pp. 185-191. (In Russian)

4. Khizhnyak A. A., Dubovskaya S. S., Mikhnevich K. G., Bausov E. A. Influence of general anesthesia on the degree of cognitive changes in elderly patients with urgent surgical pathology. Meditsina neotlozhnykh sostoyaniy, 2015, vol. 5, no. 68, pp. 140-143. (In Russian)

5. Shchaeva S. N. Surgical treatment of colorectal cancer complicated by acute intestinal obstruction. Onkologicheskaya koloproktologiya, 2016, no. 3, pp. 8-16. (In Russian)

6. Chen G., Zhou Y., Shi Q., Zhou H. Comparison of early recovery and cognitive function after desflurane and sevoflurane anaesthesia in elderly patients: A meta-analysis of randomized controlled trials. Int. Med. Res., 2015, vol. 43, no. 5, pp. 619-628.

7. Feinkohl I., Winterer G., Spies C. D., Pischon T. Cognitive Reserve and the Risk of Postoperative Cognitive Dysfunction. Dtsch. Arztebl. Int., 2017, vol. 114, no. 7, pp. 110-117.

8. Krings M., Hollig A., Liu J., Grusser L., Rossaint R., Coburn M. Desflurane impairs outcome of organotypic hippocampal slices in an in vitro model of traumatic brain injury. Med. Gas. Res., 2016, vol. 6, no. 1, pp. 3-9.

Received: February 10, 2021

Accepted: March 25, 2021

Authors' information:

Nikolay I. Glushkov — MD, Professor; nikolay.glushkov@szgmu.ru

Timofey L. Gorshenin — PhD, Associate Professor; tgorshenin@mail.ru

Mariya A.Privalova - PhD, Associate Professor; privamariya@yandex.ru

Sabina S.Dulaeva — PhD; dulaevaskszgmu@mail.ru

GrigoriyS.Gugalev _ MD; gugalev@mail.ru 